\title{
A prospective echocardiographic evaluation of pulmonary hypertension in chronic hemodialysis patients in the United States: prevalence and clinical significance
}

\author{
This article was published in the following Dove Press journal: \\ International Journal of General Medicine \\ 6 September 2010 \\ Number of times this article has been viewed
}

\author{
Kumudha Ramasubbu' \\ Anita Deswal' \\ Cheryl Herdejurgen ${ }^{2}$ \\ David Aguilar ${ }^{\prime}$ \\ Adaani E Frost ${ }^{2}$ \\ 'Section of Cardiology, Michael E \\ DeBakey VA Medical Center and \\ Baylor College of Medicine, \\ Houston, Texas, USA; ${ }^{2}$ Section \\ of Pulmonary and Critical Care \\ Medicine, Baylor College of \\ Medicine, Houston, Texas, USA
}

\begin{abstract}
Background: Pulmonary hypertension (PH), a disease which carries substantial morbidity and mortality, has been reported to occur in $25 \%-45 \%$ of dialysis patients. No prospective evaluation of the prevalence or clinical significance of $\mathrm{PH}$ in chronic dialysis patients in the United States (US) has been undertaken.

Methods: Echocardiograms were performed prospectively in chronic hemodialysis patients prior to dialysis at a single dialysis center. $\mathrm{PH}$ was defined as a tricuspid regurgitant jet $\geq 2.5 \mathrm{~m} / \mathrm{s}$ and "more severe $\mathrm{PH}$ " as $\geq 3.0 \mathrm{~m} / \mathrm{s}$. Clinical outcomes recovered were all-cause hospitalizations and death at 12 months.

Results: In a cohort of 90 patients, 42 patients (47\%) met the definition of $\mathrm{PH}$. Of those, 18 patients (20\%) met the definition of more severe PH. At 12 months, mortality was significantly higher in patients with $\mathrm{PH}(26 \%)$ compared with patients without $\mathrm{PH}$ (6\%). All-cause hospitalizations were similar in patients with $\mathrm{PH}$ and without $\mathrm{PH}$. Echocardiographic findings suggesting impaired left ventricular function and elevated pulmonary capillary wedge pressure were significantly associated with $\mathrm{PH}$.

Conclusion: This prospective cross-sectional study of a single dialysis unit suggests that PH may be present in nearly half of US dialysis patients and when present is associated with increased mortality. Echocardiographic findings demonstrate an association between elevated filling pressures, elevated pulmonary artery pressures, and higher mortality, suggesting that the PH may be secondary to diastolic dysfunction and compounded by volume overload.
\end{abstract}

Keywords: renal failure, pulmonary hypertension, diastolic dysfunction

\section{Background}

Pulmonary hypertension $(\mathrm{PH})$ regardless of etiology has been associated with increased morbidity and mortality. In patients with end-stage renal disease (ESRD) requiring chronic hemodialysis (HD) retrospective record reviews of largely non-US populations suggest that $\mathrm{PH}$ occurs in about $25 \%-45 \%$ of patients. ${ }^{1-3}$ Various mechanisms have been postulated for its development, including disturbances in endothelial and vascular smooth muscle function, ${ }^{4,5}$ high output state ${ }^{3,6}$ related to grafts and fistulas, microbubble pulmonary emboli ${ }^{7}$ and pre-existing or acquired left-sided cardiac dysfunction. ${ }^{3,8}$ It is estimated that there are about 350,000 people receiving chronic HD in the US. ${ }^{9}$ The US dialysis patient demographic differs substantially from other reported populations with theoretically different prevalence and outcome of $\mathrm{PH}$. Despite the potential burden of pulmonary hypertension in this large population, prospective data
Correspondence: Adaani Frost MS 62I, Baylor Clinic, Baylor College of Medicine, 6620 Main, Houston, Texas, USA

Tel + I 7137982400

Fax +I 7137982688

Email frost@bcm.edu 
regarding the prevalence of $\mathrm{PH}$, clinical determinants, and prognostic significance is limited. Thus, the purpose of this study was to prospectively determine the prevalence of $\mathrm{PH}$ by echocardiography in dialysis patients in a single dialysis center in the US and identify the clinical significance of $\mathrm{PH}$ on all-cause mortality and morbidity.

\section{Methods}

We prospectively performed predialysis echocardiograms on all patients routinely attending a single dialysis center. Echocardiograms were performed predialysis as opposed to post dialysis as it was felt that the predialysis status of the patient more closely reflects the chronic volume status of the patient than the immediate post dialysis "dry weight" state. Baseline demographics were collected through review of the medical records. It was attempted to consent, enroll, and recover data on all the patients in this dialysis unit. All aspects of this study were approved by the Baylor institutional review board, Fresenius (the dialysis unit operator), and the medical director(s) of the dialysis unit.

\section{Echocardiograms and estimation of pulmonary hypertension}

Complete echocardiograms (2-dimensional, M-Mode, and Doppler studies) were performed (using the Biosound system), digitally stored and analyzed. Standard 2D echocardiographic parameters of cardiac structure and function, Doppler assessment of pulmonary veins, mitral inflow, tricuspid inflow, left ventricular outflow tract, as well as tissue Doppler imaging at the mitral and tricuspid annulus were acquired with the patient in the left lateral position according to recommendations from the American Society of Echocardiography. ${ }^{10-13}$ All echocardiograms were analyzed by a single reader, who was aware that all patients were dialysis-dependent patients but was blinded to additional clinical and outcomes data.

Previous studies calculated pulmonary artery systolic pressure (PAP) echocardiographically using the Bernoulli equation: $\mathrm{PAP}=4 \times$ (peak tricuspid regurgitant $(\mathrm{TR})$ jet velocity) ${ }^{2}+10 \mathrm{mmHg}$ (estimated right atrial pressure (RAP)). As the RAP estimate is yet another estimate, to maximize the integrity of the data, $\mathrm{PH}$ was defined by the TR jet only. Thus, in the present study, $\mathrm{PH}$ was defined as a TR jet $\geq 2.5 \mathrm{~m} / \mathrm{s}$ (this would be approximately equivalent to PAP $\geq 35 \mathrm{mmHg}$ assuming a RAP of $10 \mathrm{mmHg}$ ); 'more severe PH' as TR jet $\geq 3.0 \mathrm{~m} / \mathrm{s}$. This methodology would underestimate PAP compared with prior studies but would more strictly define patients with PH. Patients with insufficient
TR jet who had echo-Doppler characteristics similar to those with normal TR jet velocity and no indirect echo-Doppler evidence of $\mathrm{PH}$ (37 patients), were grouped with patients without PH (11 patients). Patients were divided into 3 groups based on peak TR jet velocity: group 1 , no TR and TR $<2.5 \mathrm{~m} / \mathrm{s}$; group 2, TR $2.5-3.0 \mathrm{~m} / \mathrm{s}$; group 3 , TR $>3.0 \mathrm{~m} / \mathrm{s}$.

\section{Clinical outcomes}

Data on all-cause hospitalizations and death at 4, 8, and 12 months post echocardiogram was collected. For hospitalization data, complete follow up was available in 76 patients. For the survival analysis, all 90 patients were accounted for either through chart review or the United States Renal Data System database. The research nurse recording outcomes data was blinded to the results of the echo data.

\section{Statistical analysis}

Differences across the 3 groups were examined using ANOVA for continuous variables and the Chi-square test for categorical variables. Variables that were not normally distributed were examined using non-parametric tests. The data are presented as mean and standard deviation unless otherwise specified.

For survival analysis, Kaplan Meier survival curves were generated, and a log rank test was used to assess for statistically significant differences between the groups.

\section{Results}

Of 133 patients attending the dialysis clinic, 103 consented to participation between May 2006 and May 2007. 10 patients relocated prior to completion of the echocardiogram, and 3 patients were excluded due to technically inadequate echocardiograms. Thus, the cohort consisted of 90 consecutively consented and enrolled patients.

\section{Clinical characteristics}

The baseline characteristics of the patients are shown in Table 1 . The majority of patients were male (66\%), with an average age of $58 \pm 15$ years. $64 \%$ of the patients were African American, 18\% were Hispanic, and 18\% Caucasian. The most frequent cause of ESRD requiring $\mathrm{HD}$ was a combination of diabetes and hypertension (33\%) followed by hypertension alone $(30 \%)$, other causes $(28 \%)$, and lastly diabetes alone ( $9 \%$ ). For HD access, the majority of patients had arteriovenous grafts (AVGs) (44\%) followed by arteriovenous fistulas (AVFs) (40\%) and catheters (16\%). The average time on HD at the time of echocardiogram was $3.7 \pm 2.8$ years. 
Table I Baseline clinical characteristics

\begin{tabular}{|c|c|c|c|c|c|}
\hline & $\begin{array}{l}\text { All } \\
n=90\end{array}$ & $\begin{array}{l}<2.5 \mathrm{~m} / \mathrm{s} \\
\mathrm{n}=48\end{array}$ & $\begin{array}{l}2.5-3.0 \mathrm{~m} / \mathrm{s} \\
\mathrm{n}=24\end{array}$ & $\begin{array}{l}>3.0 \mathrm{~m} / \mathrm{s} \\
\mathrm{n}=18\end{array}$ & $P$-value \\
\hline $\begin{array}{l}\text { Age } \\
\text { (years) }\end{array}$ & $58.3 \pm 15.4$ & $54.5 \pm 14.3$ & $62.5 \pm 13.6$ & $62.4 \pm 18.3$ & 0.05 \\
\hline $\begin{array}{l}\text { Gender } \\
\text { (\% male) }\end{array}$ & $59 M(66 \%)$ & $30 M(63 \%)$ & $20 M(83 \%)$ & $9 M(50 \%)$ & 0.06 \\
\hline \multicolumn{6}{|l|}{ Ethnicity } \\
\hline $\mathrm{AA}$ & 58 (64\%) & 35 (73\%) & I 3 (54\%) & 10 (56\%) & \\
\hline C & $16(18 \%)$ & 7 (I5\%) & 3 (I3\%) & $6(33 \%)$ & 0.07 \\
\hline $\mathrm{H}$ & $16(18 \%)$ & $6(13 \%)$ & 8 (33\%) & 2 (II\%) & \\
\hline BMI & $27.2 \pm 6.0$ & $29.6 \pm 5.9$ & $25.1 \pm 4.3$ & $24.0 \pm 5.7$ & $<0.02$ \\
\hline \multicolumn{6}{|c|}{ Dialysis access } \\
\hline AVF & 35 (40\%) & 20 (43\%) & 12 (52\%) & $3(17 \%)$ & \\
\hline AVG & 39 (44\%) & 20 (43\%) & 8 (35\%) & II (6I\%) & 0.23 \\
\hline $\mathrm{Ca}$ & 14 (16\%) & 7 (I5\%) & $3(13 \%)$ & 4 (22\%) & \\
\hline $\begin{array}{l}\text { Years on } \\
\text { dialysis }\end{array}$ & $3.6 \pm 2.9$ & $3.8 \pm 2.7$ & $3.1 \pm 2.8$ & $3.6 \pm 3.3$ & 0.67 \\
\hline
\end{tabular}

Abbreviations: F, female; M, male; AA, African American; C, Caucasian; $H$, Hispanic; BMI, body mass index; AVF, arteriovenous fistula;AVG, arteriovenous graft; $\mathrm{Ca}$, catheter.

\section{Pulmonary hypertension}

42 patients $(47 \%)$ met the definition of $\mathrm{PH}$ of whom 18 patients $(20 \%)$ had more severe $\mathrm{PH}$. Patients with $\mathrm{PH}$ were older, and there was a trend for a female predominance in those with more severe $\mathrm{PH}$; however, this did not reach statistical significance (Table 1). Between the 3 groups, no significant differences were noted in the distribution of different ethnicities, type of access, years on HD, incidence of diabetes, hypertension, or history of coronary artery disease. Patients with $\mathrm{PH}$ did have a significantly lower body mass index (BMI) $(P<0.02)$. Laboratory parameters such as haptoglobin, hemoglobin and LDH (potential indicators of hemolysis) were not significantly different between the 3 groups (data not shown).

Echocardiographic parameters are demonstrated in Table 2. As expected, patients with PH had larger right atrial (RA) and right ventricular (RV) sizes, higher RAP and a trend towards decreased RV function. Left ventricular (LV) size did not change with increasing TR jet velocity; however, a trend towards more LV hypertrophy was noted. The mean LV ejection fraction (LVEF) in all patients was $58.4 \% \pm 11 \%$ (range $22 \%-70 \%$ ). With increasing TR jet velocity, a significant decrease in LV systolic function was noted. However, even in patients with TR $\geq 3 \mathrm{~m} / \mathrm{s}$, mean LVEF was preserved at $53.2 \% \pm 14.7 \%$. Patients with PH had significantly higher estimates of left sided filling pressures. Consistent with these findings, there was a trend towards larger left atrial size with increasing PAP (Table 2). A pericardial effusion was more frequently present in
Table 2 Echocardiographic parameters

\begin{tabular}{|c|c|c|c|c|}
\hline TR velocity & $\begin{array}{l}<2.5 \mathrm{~m} / \mathrm{s} \\
\mathrm{n}=48\end{array}$ & $\begin{array}{l}2.5-3.0 \mathrm{~m} / \mathrm{s} \\
\mathrm{n}=24\end{array}$ & $\begin{array}{l}>3.0 \mathrm{~m} / \mathrm{s} \\
\mathrm{n}=18\end{array}$ & $P$-value \\
\hline \multicolumn{5}{|c|}{ Right heart echo parameters } \\
\hline $\mathrm{RA}$ volume $(\mathrm{mL})$ & $41.6 \pm 20.3$ & $51 \pm 20.3$ & $70.1 \pm 27.9$ & $<0.02$ \\
\hline $\begin{array}{l}\text { RV apical } \\
\text { diameter }(\mathrm{cm})\end{array}$ & $3.5 \pm 0.7$ & $3.6 \pm 0.5$ & $4.2 \pm 0.7$ & 0.003 \\
\hline RV Tei & $0.14 \pm 0.2$ & $0.19 \pm 0.19$ & $0.28 \pm 0.17$ & 0.053 \\
\hline $\begin{array}{l}\text { Annular } \\
\text { descent }(\mathrm{cm})\end{array}$ & $1.9 \pm 0.6$ & $1.8 \pm 0.4$ & $1.6 \pm 0.7$ & 0.29 \\
\hline $\begin{array}{l}\mathrm{RV} \text { fractional } \\
\text { shortening }\end{array}$ & $40.8 \pm 6.3$ & $4 I \pm 8.7$ & $35.4 \pm 9.5$ & 0.1 \\
\hline RAP $(\mathrm{mmHg})$ & $7.4 \pm 3.4$ & $9.6 \pm 4.1$ & $12.8 \pm 4.6$ & $<0.02$ \\
\hline \multicolumn{5}{|c|}{ Left heart echo parameters } \\
\hline $\operatorname{LVID}(\mathrm{cm})$ & $4.5 \pm 0.7$ & $4.7 \pm 0.6$ & $4.6 \pm 0.7$ & 0.534 \\
\hline LVEF (\%) & $61.1 \pm 7.4$ & $56.9 \pm 11.2$ & $53.2 \pm 14.7$ & 0.017 \\
\hline LA volume $(\mathrm{mL})$ & $60.7 \pm 22.1$ & $62.5 \pm 19.4$ & $74.8 \pm 26.5$ & 0.085 \\
\hline PCWP (mmHg) & $15.6 \pm 5.3$ & $19.5 \pm 7.7$ & $24.9 \pm 7.9$ & $<0.02$ \\
\hline $\mathrm{LVH}^{\mathrm{a}}(\mathrm{cm})$ & $1.4 \pm 0.6$ & $1.5 \pm 0.6$ & $1.9 \pm 0.6$ & 0.1 \\
\hline
\end{tabular}

Note: average wall thickness of interventricular septum and posterior wall measured in the parasternal long axis view.

Abbreviations: TR, tricuspid regurgitant; RA, right atrial; RV, right ventricular; RAP, right atrial pressure; LVID, left ventricular internal dimension; LVEF, left ventricular ejection fraction; LA, left atrial; PCWP, pulmonary capillary wedge pressure.

patients with higher PAP ( $0 \%$ in group $1,8 \%$ in group 2 , and $33 \%$ in group 3 ). The occurrence of significant valvular disease was rare in all groups.

Echocardiographic data were available for the calculation of pulmonary capillary wedge pressure (PCWP) in 70 patients. Patients with $\mathrm{PH}$ had significantly higher PCWP (Table 2). Correlation analysis revealed a significant correlation between PAP and PCWP (Pearson correlation coefficient $=0.5, P=0.001$ ).

\section{Clinical outcome}

At 12 months, a total of 14 deaths (15.6\%) had occurred. Mortality was significantly higher in patients with $\mathrm{PH}(26 \%)$ compared with patients without $\mathrm{PH}(6 \%)$, and this was driven largely by increased mortality in patients with more significant PH (TR $\geq 3 \mathrm{~m} / \mathrm{s}$ ). By 12 months, mortality was $44 \%(8 / 18)$ in group 3 versus $6 \%(3 / 48)$ and $12.5 \%(3 / 24)$ in groups 1 and 2, respectively $(P=0.001)$. The Kaplan Meier survival curves are shown in Figure 1.

In exploratory analysis comparing survivors to non-survivors (Table 3), there was no significant difference in age, race, gender, BMI, access type, and incidence of diabetes or hypertension, or history of coronary artery disease between the 2 groups. However, patients who died had been on HD for a significantly longer duration than survivors. In addition, patients who died had larger RA and RV sizes, worse RV function, more severe TR, 


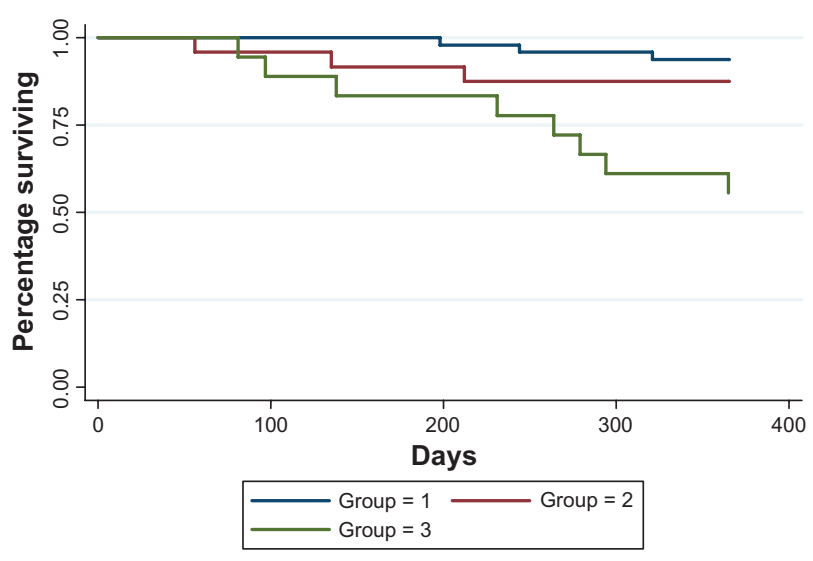

Figure I Kaplan Meier survival estimates based on presence, absence, and degree of $\mathrm{PH}$ by TR jet: group I = no TR, and TR $<2.5 \mathrm{~m} / \mathrm{s}$; group $2=\mathrm{TR} 2.5-3.0 \mathrm{~m} / \mathrm{s}$; group $3=$ TR $>3.0 \mathrm{~m} / \mathrm{s}(P=0.0004)$. At 12 months, mortality was $44 \%(8 / 18)$ in group 3 versus $6 \%(3 / 48)$ and $12.5 \%(3 / 24)$ in groups I and 2 , respectively $(P=0.00 I)$. The $P=0.0004$ is based on the time to event analysis and signifies an overall difference between the 3 curves/groups. $P=0.00 \mathrm{I}$ is based on a chi-square test for the number of deaths by 12 months between the 3 groups.

Abbreviation: TR, tricuspid regurgitant.

and significantly higher RAP and PAP. There was no significant difference in LV size between the 2 groups, but non-survivors did show a trend towards lower LVEF than survivors. Moreover, PCWP was significantly higher in non-survivors (Table 3).

Table 3 Analysis by survivors and non-survivors

\begin{tabular}{|c|c|c|c|}
\hline & $\begin{array}{l}\text { Survivors } \\
n=76\end{array}$ & $\begin{array}{l}\text { Non-survivors } \\
n=14\end{array}$ & $P$-value \\
\hline Age & $57.4 \pm 15$ & $62.79 \pm 16.8$ & 0.23 \\
\hline Race & $49 \mathrm{AA}, \mathrm{I4C}, 13 \mathrm{H}$ & $9 \mathrm{AA}, 2 \mathrm{C}, 3 \mathrm{H}$ & 0.89 \\
\hline Gender & $52 \mathrm{M}, 24 \mathrm{~F}$ & $7 \mathrm{M}, 7 \mathrm{~F}$ & 0.18 \\
\hline BMI & $27.549 \pm 6$ & $25.55 \pm 5.8$ & 0.27 \\
\hline Access & 33AVF, 32AVG, I0Ca & 6AVF, 3AVG, 4Ca & 0.2 \\
\hline Years on HD & $3.4 \pm 2.6$ & $5.4 \pm 3.4$ & 0.02 \\
\hline RA volume & $47.4 \pm 23.4$ & $63.4 \pm 25.2$ & 0.03 \\
\hline $\begin{array}{l}\text { RA fractional } \\
\text { shortening }\end{array}$ & $38.8 \pm 9.4$ & $28.7 \pm 15.7$ & 0.008 \\
\hline RV apical diameter & $3.6 \pm 0.7$ & $4.0 \pm 0.6$ & 0.07 \\
\hline $\mathrm{RV}$ function & $\mathrm{I} . \mathrm{I} \pm 0.4$ & $1.7 \pm 0.9$ & 0.001 \\
\hline Annular descent & $1.8 \pm 0.6$ & $1.5 \pm 0.7$ & 0.06 \\
\hline $\begin{array}{l}\text { RV fractional } \\
\text { shortening }\end{array}$ & $40.5 \pm 7.2$ & $35 \pm 10.9$ & 0.07 \\
\hline TR severity & $1.4 \pm 0.7$ & $1.9 \pm 1.0$ & 0.01 \\
\hline RAP & $8.7 \pm 3.9$ & $12.3 \pm 5.6$ & 0.006 \\
\hline PAP & $39.4 \pm 10.5$ & $56.9 \pm 19.7$ & $<0.02$ \\
\hline LVID & $4.6 \pm 0.6$ & $4.6 \pm 0.8$ & 0.87 \\
\hline LVEF & $59.1 \pm 9.7$ & $54.7 \pm 14.5$ & 0.16 \\
\hline PCWP & $17.3 \pm 6.6$ & $23.9 \pm 8.8$ & 0.01 \\
\hline
\end{tabular}

Abbreviations: F, female; M, male; AA, African American; C, Caucasian; H, Hispanic; AVF, arteriovenous fistula; AVG, arteriovenous graft; $\mathrm{Ca}$, Catheter; BMI, body mass index; HD, hemodialysis; RA, right atrial; RV, right ventricular; TR, tricuspid regurgitant; RAP, right atrial pressure; PAP, pulmonary artery pressure; LVID, left ventricular internal dimension; LVEF, left ventricular ejection fraction; PCWP, pulmonary capillary wedge pressure.

\section{Discussion}

Previously reported data has demonstrated that $\mathrm{PH}$ occurs in about $25 \%-45 \%$ of patients with ESRD on HD. ${ }^{1-3}$ However, these analyses were retrospective, based on patients undergoing echocardiography for clinical indications (preselection bias) and were performed in non-US countries (Table 4). This study is the first prospective evaluation of $\mathrm{PH}$ in dialysis patients in the US. Our study revealed that $\mathrm{PH}$ is highly prevalent in dialysis patients (47\%), with $20 \%$ of the patients having echocardiographic evidence of more severe PH. This study further demonstrates that the presence of $\mathrm{PH}$ is associated with a significant increase in mortality with a 12-month mortality of $44 \%$ in patients with more severe $\mathrm{PH}$. This is in relation to annual mortality rates of approximately $20 \%$ in dialysis patients in the US. ${ }^{9}$ Not surprisingly, this study provides evidence that the development of $\mathrm{PH}$ in dialysis patients may reflect the impact of chronic volume overload and chronically elevated left heart filling pressures.

Several mechanisms have been proposed for the development of $\mathrm{PH}$ in dialysis patients, and ultimately, a combination of multiple factors likely contributes to its development. PH may evolve due to the inability of the pulmonary circulation to accommodate increased cardiac output (resulting from increased volume, anemia, arteriovenous fistula) or as a result of increased pulmonary vascular stiffness due to endothelial dysfunction (decreased nitric oxide). ${ }^{3,5,6}$ In the current study, neither type of access nor anemia were associated with PH. The only echocardiographic parameters that were significantly associated with PH in the current study were PCWP and LV function. $63 \%$ of patients had echocardiographic evidence of elevated PCWP, and an elevated PCWP was associated with elevated RAP and PAP. Moreover, correlation analysis revealed a significant correlation between PAP and PCWP, suggesting that elevated PCWP may be a major contributor to PAP elevation.

Although there was a significant decrease in LV function with increasing PAP, the mean LVEF in patients with $\mathrm{PH}$ was still preserved (mean LVEF $53.2 \% \pm 14.7 \%$ ). Similarly, in subjects with higher estimates of PCWP, there was only a trend towards decreased LVEF. These findings suggest that diastolic heart failure with preserved LV systolic function may be the mechanism for elevated filling pressures in a significant proportion of patients. The elevated filling pressures in turn may contribute to the development of PH. In our study population, volume retention appeared to contribute more towards elevated filling pressures than severity of diastolic dysfunction. This is reflected by the observation that the increase in filling pressures was driven more by an increase 


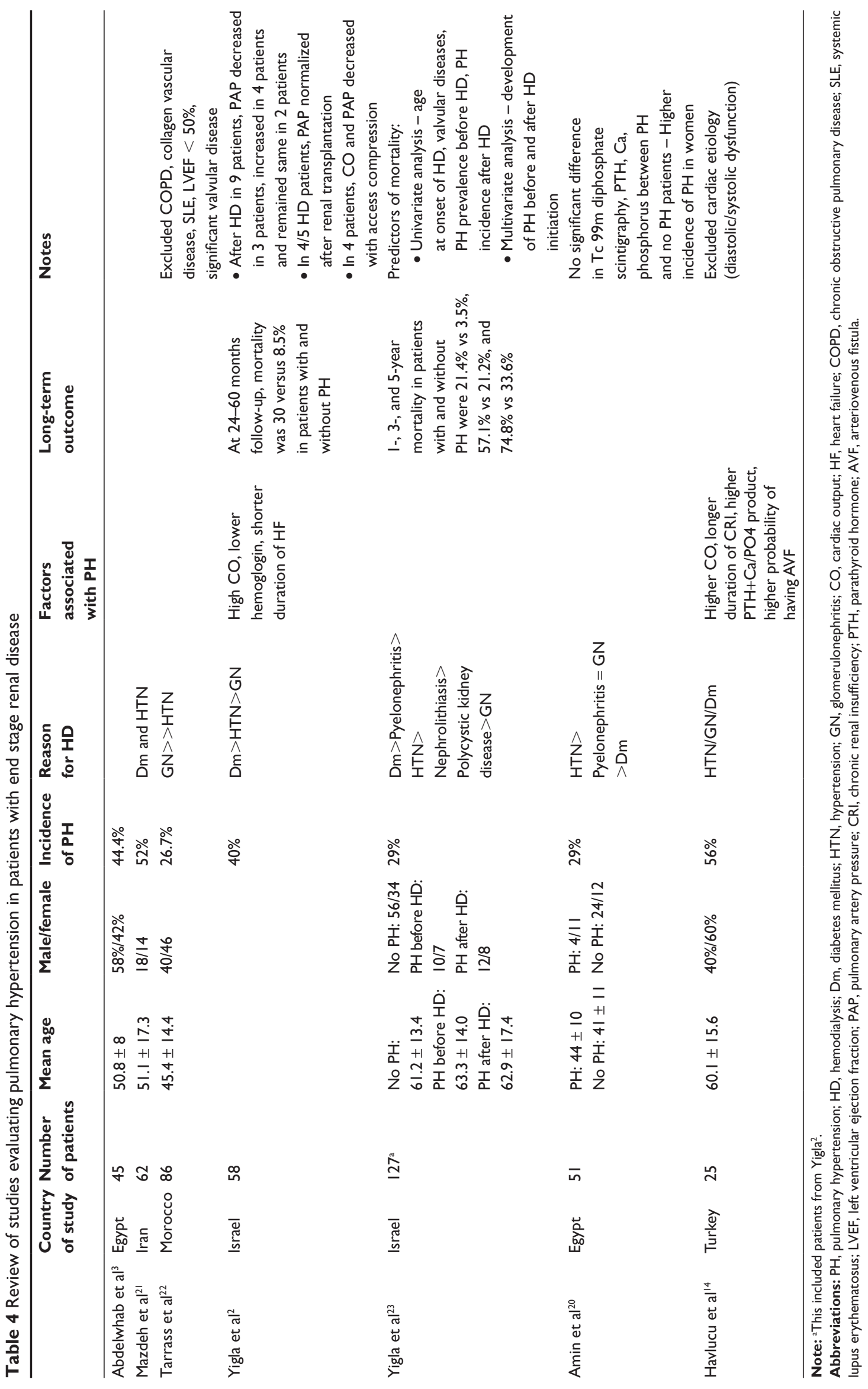


in mitral $\mathrm{E}$ wave velocity rather than a decrease in tissue Doppler E velocity. However, the potential importance of multifactorial diastolic dysfunction, an increasingly frequent cause of $\mathrm{PH}$ in the non-dialysis patient population, should not be discounted as a contributor to $\mathrm{PH}$ and its outcome in the dialysis population.

Two previous studies also suggest a causal relationship between PCWP and PAP. Havlucu et al followed 25 dialysis and 23 pre-dialysis patients for 6 months. At the end of 6 months, left atrial diameter (LAD) (reflection of left-sided filling pressures), vena cava index (VCI) (reflection of RAP), and systolic PAP improved in the dialysis patients, whereas in pre-dialysis patients, VCI did not change and LAD and PAP actually increased. The authors concluded that effective $\mathrm{HD}$ and volume control (as reflected by decrease in LAD and VCI) may have resulted in improved PAP. ${ }^{14}$

In another study, Barberato et al compared dialysis patients with normal and pseudonormal mitral inflow patterns, the latter reflecting elevated left-sided filling pressures. Interestingly, although mean LVEF was significantly lower in the pseudonormal group, it was still preserved on average ( $73 \% \pm 7 \%$ versus $65 \% \pm 10 \%, P<0.01$ ). Moreover, systolic PAP was significantly higher in the pseudonormal group $(38 \pm 11 \mathrm{mmHg}$ versus $20 \pm 6 \mathrm{mmHg}, P=0.01) .{ }^{15}$ These results further support the findings in the current study that elevated filling pressures in dialysis patients are associated with preserved LV function and elevated PAP.

In ESRD patients, even in the presence of preserved LV systolic function, diastolic abnormalities with impaired LV relaxation and increased ventricular stiffness are not infrequent. ${ }^{16-18}$ In our study population, $77 \%$ of the dialysis patients had echo evidence of abnormal diastolic function. Diastolic dysfunction in dialysis patients can be due to multiple factors. Left ventricular hypertrophy mainly as a result of hypertension is prevalent in dialysis patients and is strongly associated with impaired diastolic function. Furthermore, a large number of dialysis patients have diabetes, which by itself has been associated with increased myocardial stiffness and diastolic dysfunction. Other factors that may contribute to increased ventricular stiffness in ESRD patients include uremia and upregulation of various neurohormones. ${ }^{19}$

In dialysis patients, the impact of $\mathrm{PH}$ on clinical outcomes has not previously been prospectively studied. While this is a cross-sectional study and may have suffered from survivor bias, given that the mortality was higher in the patients with $\mathrm{PH}$, the survivor bias should predispose to an underestimation of the frequency of PH in the US dialysis patient population.
In a recently published retrospective database review of HD patients receiving echocardiograms for clinical indications, 127 dialysis patients were evaluated, and the prevalence of $\mathrm{PH}$ was found to be $29 \%$. Of the 37 patients with $\mathrm{PH}, 17$ had $\mathrm{PH}$ at initiation of $\mathrm{HD}$, and 20 patients developed $\mathrm{PH}$ after HD initiation. Survival was significantly higher in patients without PH. The 1-, 3-, and 5-year mortality in patients with and without $\mathrm{PH}$ were $21.4 \%$ versus $3.5 \%, 57.1 \%$ versus $21.2 \%$, and $74.8 \%$ versus $33.6 \%$ respectively. ${ }^{1}$ Similar findings were noted in the current study: at 12 months follow-up, mortality was $26 \%$ in patients with $\mathrm{PH}$ and $6 \%$ in patients without PH. Interestingly, with respect to all-cause hospitalizations (including emergency room visits), no significant difference was found amongst the 3 groups. Thus, morbidity by this definition amongst dialysis patients appears to be very high irrespective of PAP.

In the current study, when comparing survivors with non-survivors, PAP and PCWP were significantly higher in non-survivors. On the one hand, this may reflect the progression of diastolic heart failure with elevated PCWP eventually resulting in $\mathrm{PH}$, which then carries a poor longterm prognosis. Alternatively, $\mathrm{PH}$ may have developed as a result of other causes, may not necessarily be associated with elevated PCWP, and may thus independently be a poor prognostic marker.

No relation was found between the nature of the dialysis access and the presence of PH. This is not unexpected. There is a clear rationale for aggravation of heart failure in patients with established $\mathrm{PH}$ or diastolic dysfunction due to the higher output imposed by a chronic graft of fistula. However, there is a very low likelihood that a $25 \%-30 \%$ increase in basal cardiac output over a relatively short period of time (years as opposed to decades) would be likely to predispose to the high flow induced changes in the pulmonary vascular bed leading to $\mathrm{PH}$. The development of $\mathrm{PH}$ is remarkably infrequent (about 4\%) in patients with common congenital heart disease such as ASD.

\section{Limitations}

We included patients in whom PAP could not be measured due to insufficient TR in the normal group (group 1). We did ensure that these patients did not have any other echocardiographic signs indicating the presence of $\mathrm{PH}$. Secondly, we used a TR jet cutoff of $\geq 2.5 \mathrm{~m} / \mathrm{s}$ for the classification of $\mathrm{PH}$. Assuming a RAP of $10 \mathrm{mmHg}$, this would equate to a PAP of $\geq 35 \mathrm{mmHg}$. In the setting of lower RAP, these patients may have been misclassified as having higher PAP. Although these 2 scenarios may have led to misclassification by potentially 
including PH patients in the normal group and normal patients in the PH group, we were still able to identify a difference in prognosis between the groups. Due to the small number of overall events, a multivariable regression analysis could not be performed to evaluate the extent to which $\mathrm{PH}$ independently contributed to mortality. Thus, although PH is associated with higher mortality, our study was not able to ascertain causality versus association between $\mathrm{PH}$ and mortality or whether $\mathrm{PH}$ is merely an indicator of sicker patients. We believe, however, that this approach in this cross-sectional analysis conservatively provides a lower estimate of the prevalence and impact of $\mathrm{PH}$ in chronic ESRD patient on dialysis.

\section{Conclusion}

In this first prospective study of PH in US dialysis patients, at a single center, we found that $\mathrm{PH}$ is highly prevalent and is associated with echocardiographic evidence of elevated left-sided filling pressures and higher mortality. The clinical importance of $\mathrm{PH}$ appears to be as a marker of disease severity, as a potential target of therapy, and as an important prognostic indicator. While multiple factors may contribute to the development of $\mathrm{PH}$ in dialysis patients our results suggest that chronic volume overload, and/or diastolic dysfunction may contribute to the development of $\mathrm{PH}$, which is associated with poorer survival. This suggests that the presence of $\mathrm{PH}$ should be incorporated in the decision making for renal transplantation, since $\mathrm{PH}$ is associated with worse survival, and appears to improve after renal transplantation. ${ }^{2}$

The results of the current study demonstrating the frequency and impact of $\mathrm{PH}$ in the US dialysis population underline the importance of adequate volume removal, and potentially the importance of future therapies targeting $\mathrm{PH}$ and diastolic dysfunction.

\section{Acknowledgments}

This project was supported by a grant from the Frueauff Foundation. The authors wish to thank: Biosound for providing the ultrasound machine; Fresenius and the physicians, nurses, and patients, and Dr Wadi N Suki, Medical Director at the Medical Center Kidney Clinic, Houston, Texas for their cooperation in this study.

\section{Support and financial disclosure declaration}

Funding for this study was obtained from the Frueauff Foundation, a nonprofit, non-industry organization, which supports limited medical and scientific studies.
In addition, as stated in the acknowledgments, Biosound provided an echo machine free of charge to undertake the external echocardiograms which were done at the dialysis units.

\section{Conflict of interest}

Dr Frost has received funding for FDA approved multicenter studies in pulmonary hypertension from Bayer, Actelion, Gilead, Lilly, United Therapeutics, Novartis and Pfizer. She is on the speaker bureau and/or has received honoraria for participation in advisory boards on PH from Gilead, Pfizer, United Therapeutics and Actelion. The other authors declare no conflicts of interest.

\section{References}

1. Yigla M, Fruchter O, Aharonson D, et al. Pulmonary hypertension is an independent predictor of mortality in hemodialysis patients. Kidney Int. 2009;75:969-975.

2. Yigla M, Nakhoul F, Sabag A, et al. Pulmonary hypertension in patients with end-stage renal disease. Chest. 2003;123:1577-1582.

3. Abdelwhab S, Elshinnawy S. Pulmonary hypertension in chronic renal failure patients. Am J Nephrol. 2008;28:990-997.

4. Thambyrajah J, Landray MJ, McGlynn FJ, Jones HJ, Wheeler DC, Townend JN. Abnormalities of endothelial function in patients with predialysis renal failure. Heart. 2000;83:205-209.

5. Morris CR, Gladwin MT, Kato GJ. Nitric oxide and arginine dysregulation: a novel pathway to pulmonary hypertension in hemolytic disorders. Curr Mol Med. 2008;8:620-632.

6. Okura H, Takatsu Y. High-output heart failure as a cause of pulmonary hypertension. Intern Med. 1994;33:363-365.

7. Barak M, Katz Y. Microbubbles: pathophysiology and clinical implications. Chest. 2005;128:2918-2932.

8. Fathi R, Isbel N, Haluska B, Case C, Johnson DW, Marwick TH. Correlates of subclinical left ventricular dysfunction in ESRD. Am J Kidney Dis. 2003;41:1016-1025.

9. USRDS 2008 Annual Data Report [report on the Internet]. United States Renal Data System. Available from: www.usrds.org/adr.htm. 2009.

10. Quinones MA, Otto CM, Stoddard M, Waggoner A, Zoghbi WA. Recommendations for quantification of Doppler echocardiography: a report from the Doppler Quantification Task Force of the Nomenclature and Standards Committee of the American Society of Echocardiography. $J$ Am Soc Echocardiogr. 2002;15:167-184.

11. Lang RM, Bierig M, Devereux RB, et al. Recommendations for chamber quantification: a report from the American Society of Echocardiography's Guidelines and Standards Committee and the Chamber Quantification Writing Group, developed in conjunction with the European Association of Echocardiography, a branch of the European Society of Cardiology. J Am Soc Echocardiogr. 2005;18: $1440-1463$.

12. Nagueh SF, Appleton CP, Gillebert TC, et al. Recommendations for the evaluation of left ventricular diastolic function by echocardiography. JAm Soc Echocardiogr. 2009;22:107-133.

13. Horton KD, Meece RW, Hill JC. Assessment of the right ventricle by echocardiography: a primer for cardiac sonographers. J Am Soc Echocardiogr. 2009;22:776-792.

14. Havlucu Y, Kursat S, Ekmekci C, et al. Pulmonary hypertension in patients with chronic renal failure. Respiration. 2007;74:503-510.

15. Barberato SH, Pecoits-Filho R. Usefulness of left atrial volume for the differentiation of normal from pseudonormal diastolic function pattern in patients on hemodialysis. JAm Soc Echocardiogr. 2007;20: 359-365. 
16. Mall G, Huther W, Schneider J, Lundin P, Ritz E. Diffuse intermyocardiocytic fibrosis in uraemic patients. Nephrol Dial Transplant. 1990;5:39-44.

17 Mall G, Rambausek M, Neumeister A, Kollmar S, Vetterlein F, Ritz E. Myocardial interstitial fibrosis in experimental uremia - implications for cardiac compliance. Kidney Int. 1988;33:804-811.

18. London GM, Parfrey PS. Cardiac disease in chronic uremia: pathogenesis. Adv Ren Replace Ther. 1997;4:194-211.

19. London GM. Left ventricular alterations and end-stage renal disease. Nephrol Dial Transplant. 2002;17 Suppl 1:29-36.

20. Amin M, Fawzy A, Hamid MA, Elhendy A. Pulmonary hypertension in patients with chronic renal failure: role of parathyroid hormone and pulmonary artery calcifications. Chest. 2003;124:2093-2097.
21. Mahdavi-Mazdeh M, Alijavad-Mousavi S, Yahyazadeh H, Azadi M, Yoosefnejad H, Ataiipoor Y. Pulmonary hypertension in hemodialysis patients. Saudi J Kidney Dis Transpl. 2008;19:189-193.

22. Tarrass F, Benjelloun M, Medkouri G, Hachim K, Benghanem MG, Ramdani B. Doppler echocardiograph evaluation of pulmonary hypertension in patients undergoing hemodialysis. Hemodial Int. 2006;10:356-359.

23. Yigla M, Fruchter O, Aharonson D, et al. Pulmonary hypertension is an independent predictor of mortality in hemodialysis patients. Kidney Int. 2009;75:969-975.

\section{Publish your work in this journal}

The International Journal of General Medicine is an international, peer-reviewed open-access journal that focuses on general and internal medicine, pathogenesis, epidemiology, diagnosis, monitoring and treatment protocols. The journal is characterized by the rapid reporting of reviews, original research and clinical studies across all disease areas.
A key focus is the elucidation of disease processes and management protocols resulting in improved outcomes for the patient. The manuscript management system is completely online and includes a very quick and fair peer-review system. Visit http://www.dovepress.com/ testimonials.php to read real quotes from published authors.

Submit your manuscript here: http://www.dovepress.com/international-journal-of-general-medicine-journal 